\title{
Influência da somatotropina recombinante bovina no desenvolvimento folicular e na coleta de embriões em éguas
}

[Influence of bovine recombinant somatotropin in the follicular development and embryo colletion in mares ]

\author{
L.E.P.A. Ferreira ${ }^{1,2}$, A. Wischral ${ }^{1,3}$, C.C. Bartolomeu ${ }^{1,3}$, L.A.C. Costa $^{4}$, A.F. Soares ${ }^{1,3}$ \\ ${ }^{1}$ Programa de pós-graduação - Universidade Federal Rural de Pernambuco - UFRPE - Recife, PE \\ ${ }^{2}$ Instituto Federal de Educação - Ciência e tecnologia de Pernambuco - IFPE - Belo Jardim, PE \\ ${ }^{3}$ Universidade Federal Rural de Pernambuco - UFRPE - Recife, PE \\ ${ }^{4}$ Médico veterinário autônomo - Garanhuns, PE
}

\begin{abstract}
RESUMO
Dez éguas, sem raça definida, foram submetidas a avaliações ultrassonográficas durante o intervalo interovulatório, avaliando-se folículos $\geq 5 \mathrm{~mm}$. Cinco éguas foram tratadas com $500 \mathrm{mg}$ de $\mathrm{r}$-bST no primeiro e no $14^{\circ}$ dia pós-ovulação (grupo GT), e as demais com soro fisiológico (grupo GC). Quando o folículo dominante atingiu diâmetro $\geq 40 \mathrm{~mm}$, foram induzidas com hCG e inseminadas 24 horas após, sendo submetidas à coleta de embrião seis dias após a ovulação. Os dados foram agrupados de acordo com o diâmetro do folículo dominante nas fases de emergência, divergência, dominância, pré-ovulatória, indução, inseminação e ovulação. Todas as éguas foram usadas duas vezes, no mesmo grupo. O GT apresentou crescimento folicular precoce para as fases de emergência, divergência, dominância e préovulatória, assim como para o seu maior folículo subordinado, que cresceu mais cedo. As taxas de recuperação foram de $90 \%$ (GC) e $70 \%$ (GT), em 16 estruturas coletadas, obtendo-se uma não fecundada e um blastocisto inicial para o grupo GC; os demais, no estágio de mórula, apresentaram comportamento semelhante entre os grupos. Conclui-se que a r-bST influencia a dinâmica folicular de éguas, levando a uma antecipação do desenvolvimento folicular, que pode ser utilizada para encurtar o ciclo estral.
\end{abstract}

Palavras-chave: hormônio do crescimento, dinâmica folicular, folículo dominante, folículo subordinado

\begin{abstract}
Ten undefined mare breeds were submitted to ultrasonographic evaluations during the interovulatory interval, evaluating follicles measuring $\geq 5 \mathrm{~mm}$. Five mares were treated with $500 \mathrm{mg} r$-bST on the first and the 14th day after ovulation (TG group), and the others with saline (CG group). When the dominant follicle reached a diameter $\geq 40 \mathrm{~mm}$ the ovulation was induced with $h C G$, and the mares were inseminated 24 hours later and submitted to embryo collection six days after ovulation. The data were grouped according to the diameter of the dominant follicle in the emergence, divergence, dominance, preovulatory, induction, insemination and ovulation phases. All mares were used twice, in the same group. The GT showed early follicular growth for the emergence, divergence, dominance and preovulatory phases, as well as for its greater subordinate follicle, growing earlier. The recovery rates were 90\% (CG) and 70\% (TG), and 16 structures were collected, obtaining an unfertilized embryo and an initial blastocyst for the CG group, the others in the morula stage behaved similarly between the groups. It can be concluded that $r$ - $b S T$ influences the follicular dynamics of the mares, leading to an anticipation of the follicular development that can be used to shorten the estrous cycle.
\end{abstract}

Keywords: growth hormone, follicular dynamic, dominant follicle, subordinate follicle

Recebido em 8 de novembro de 2018

Aceito em 27 de março de 2019

E-mail: 1_eduardo_@hotmail.com 


\section{INTRODUÇÃO}

A somatotropina, hormônio de crescimento $(\mathrm{GH})$ sintetizado e secretado pela hipófise anterior, vem sendo estudada e demonstrada como estimuladora da fisiologia reprodutiva (Cochran et al., 1999; Zulu et al., 2002), porém a égua tem sido pouco utilizada como modelo experimental (Cochran et al., 1999; Gomes, 2007). No entanto, a espécie equina é um excelente modelo para as demais espécies monovulatórias, inclusive a humana (Alves et al., 2016), apesar de ainda necessitar melhorar seus índices reprodutivos em manejos comerciais. O efeito anabolizante da somatotropina recombinante bovina, equina e suína em equinos já foi estudado. Os resultados mostraram que a somatotropina suína causa exacerbada reação no local de aplicação, e a equina, além de ser de difícil aquisição, necessita de aplicação diária. Já a somatotropina recombinante bovina (r-bST) é de fácil aquisição, apresenta baixa reação local e mantém sua ação farmacológica por 14 dias, devido a seu veículo de aplicação, além de apresentar homologia de $89 \%$ com a molécula equina (De Kock et al., 2001).

A comprovação da r-bST como biologicamente ativa em equinos foi demonstrada por meio das dosagens do fator de crescimento semelhante à insulina tipo um (IGF-I) (Buonomo et al., 1996; De Kock et al., 2001), a principal somatomedina mediadora de sua função (Norman e Litwack, 1997). Nas fêmeas das mais diversas espécies, o conjunto da r-bST e da IGF-I potencializa o crescimento folicular e oocitário Gong et al., 1993; Sá Filho et al., 2009) e o desenvolvimento embrionário (Moreira et al., 2002), estando seus níveis elevados relacionados à maior ocorrência de partos gemelares (Cushman et al., 2000), além de apresentarem receptores no hipotálamo, na hipófise, no corpo lúteo, nos folículos ovarianos, nos ovidutos, no endométrio, no miométrio e na placenta (Kirby et al., 1997). Tais ações ocorrem por mecanismos autócrinos, parácrinos e endócrinos, o que demonstra que os tecidos reprodutivos não são apenas locais de ação, mas também de síntese (Hull e Harvey, 2014).

As IGFs estimulam a proliferação celular e a produção hormonal nas células ovarianas (Spicer et al., 1993), interferindo, assim, na dinâmica folicular (Gurgel et al., 2008). Dessa forma, acredita-se que a r-bST pode beneficiar os índices reprodutivos, principalmente na técnica de transferência de embrião (TE) na espécie equina, que tem apresentado resultados inferiores aos encontrados em outras espécies, como a bovina (Squires et al., 2003). Nesta pesquisa, objetivou-se avaliar a interferência do r-bST na dinâmica folicular e na produção de embriões em éguas.

\section{MATERIAL E MÉTODOS}

$\mathrm{O}$ experimento foi desenvolvido entre os meses de outubro e março, no agreste meridional de Pernambuco, nordeste do Brasil $\left(8^{\circ} 55^{\prime} 47^{\prime \prime} \mathrm{S}\right.$, $\left.36^{\circ} 32^{\prime} 01^{\prime \prime W}\right)$. Foram utilizadas éguas cíclicas $(\mathrm{n}=10)$, com idade e peso médio de $6,1( \pm 1,6)$ anos e $372,7( \pm 13,5) \mathrm{kg}$, respectivamente. Todas as éguas eram saudáveis e criadas extensivamente em pastejo de Digitaria decumbens, com água e sal mineral à vontade. Os procedimentos realizados com os animais seguiram as recomendações da legislação brasileira sobre procedimentos de uso científico de animais (Lei $\mathrm{n}^{\mathrm{o}} 11.794$ / 2008), com aprovação do Comitê de Ética no Uso de Animais (Ceua) da Universidade Federal Rural de Pernambuco (UFRPE) (licença no 07/2017).

As éguas foram examinadas diariamente por ultrassom equipado com transdutor transretal linear multifrequencial calibrado em $5 \mathrm{MHz}$ (M5 Vet, Mindray, China), sempre em mesmo horário, o que possibilitou a criação retroativa dos ciclos estrais, por meio do número e dos diâmetros foliculares. Aquelas que inicialmente apresentavam corpo lúteo (CL) foram medicadas com 5mg de dinoprost (prostaglandina $\mathrm{F}_{2 \alpha}$ $\mathrm{PGF}_{2 \alpha}$ ) (Lutalyse ${ }^{\circledR}$, Pfizer, Brasil). Durante as avaliações, quando o folículo dominante atingia valores acima de $35 \mathrm{~mm}$, as éguas eram induzidas a ovular com $750 \mu \mathrm{g}$ de acetato de deslorelina (Sincrorrelin ${ }^{\circledR}$, Ouro Fino, Brasil) por via intramuscular. Em seguida, quando se identificou o desaparecimento do folículo dominante, marcando o início de um ciclo estral (dia zero D0), as éguas foram tratadas por via subcutânea, ventralmente à inserção da cauda, com $500 \mathrm{mg}$ de r-bST (Lactotropin Injetável ${ }^{\circledR}$, Elanco Saúde Animal, Brasil) (grupo tratamento - GT) ou com solução fisiológica (grupo controle - GC), sendo repetidos após 14 dias (D14).

Posteriormente, quando um novo folículo dominante atingia diâmetro $\geq 40 \mathrm{~mm}$, foram 
administrados 2.500UI de gonadotrofina coriônica humana (hCG) $\left(\right.$ Vetecor $^{\circledR}$, Hertape Calier Saúde Animal S/A, Brasil), por via intravenosa, para induzir uma nova ovulação. Após 24 horas da administração da hCG, todas as éguas foram inseminadas, pelo método transcervical, com sêmen fresco contendo 1.000 x $10^{6}$ espermatozoides viáveis, provenientes do mesmo garanhão.

A ovulação do folículo dominante marcou o final do ciclo estral (DF), e as éguas foram submetidas à coleta de embrião pelo método transcervical não cirúrgico (Squires et al., 2003), seis dias após a ovulação. Para as lavagens uterinas, foram utilizados $3 \mathrm{~L}$ de solução ringer com lactato de sódio divididos igualmente em três procedimentos de lavagem. As estruturas recuperadas foram classificadas de acordo com sua morfologia e estágio, conforme proposto por Mccue (2011), observando-se o formato do embrião, a espessura e a presença de lesão na zona pelúcida e na cápsula, a uniformidade dos blastômeros e dos citoplasmas, as extrusões no espaço perivitelínico e a formação da blastocele. Os grupos foram divididos de forma aleatória, e todas as éguas foram usadas duas vezes, no mesmo grupo, respeitando-se o intervalo de dois ciclos estrais entre as repetições. Os intervalos entre as induções de ovulação foram considerados como um ciclo estral, obtendo-se, assim, 20 ciclos estrais, 10 para cada grupo.

A avaliação foi feita separando-se os dados obtidos em sete fases identificadas após avaliação retrospectiva dos diâmetros foliculares: emergência (início do crescimento do maior folículo), divergência (maior folículo com diâmetro $\geq 22 \mathrm{~mm}$ ), dominância (maior folículo com diâmetro $\geq 25 \mathrm{~mm}$ ), pré-ovulatória (maior folículo com diâmetro $\geq 35 \mathrm{~mm}$ ) (Donadeu e Pedersen, 2008), indução ovulatória (maior folículo com diâmetro $\geq 40 \mathrm{~mm}$ ), inseminação artificial (24 horas após a indução da ovulação) e ovulatória (desaparecimento do folículo dominante). Os intervalos entre fases subsequentes foram utilizados para calcular a taxa de crescimento folicular média por fase, que foi obtida por meio da média das taxas de crescimento folicular dos ciclos estrais, calculadas pela diferença entre os tamanhos foliculares de cada fase subsequente, os quais foram divididos pelos dias entre essas fases e nomeados pela fase que os iniciou.
Os dados obtidos são apresentados como média e desvio-padrão, como medidas de tendência central. Foi empregada a análise de variância (ANOVA) para um fator e, nos casos em que houve significância no teste $\mathrm{F}(\mathrm{P} \leq 0,05)$, as médias foram comparadas pelo teste de Tukey. Para as variáveis não paramétricas, na comparação entre grupos foi empregado o teste de Kruskal-Wallis, enquanto para o efeito de momento foi usado o teste de Fridman (Curi, 1998). Para as avaliações embrionárias, foi empregado o método descritivo.

\section{RESULTADOS E DISCUSSÃO}

O presente estudo é o primeiro a avaliar o tratamento com r-bST durante todo o ciclo estral de éguas submetidas à coleta de embrião, sem utilização de outro hormônio promotor do crescimento ou superovulatório. Poucas pesquisas têm utilizado o r-bST na reprodução de equinos, porém já foi demonstrado que esse hormônio é biologicamente ativo na espécie em estudo, promovendo aumento nos níveis plasmáticos de IGF-I (Buonomo et al., 1996; De Kock et al., 2001). O comportamento da onda folicular foi semelhante entre os grupos (Fig. 1), caracterizando ondas foliculares maiores primárias, conforme já descrito na literatura (Ginther, 1992, 2000). Em 100\% dos ciclos acompanhados, foram observadas ondas foliculares únicas, com presença de apenas um folículo dominante que chegou a ovular e de folículos subordinados que entraram em atresia após a definição da dominância.

O número de folículos recrutados foi semelhante entre os grupos (Fig. 2), não sendo observada influência do tratamento, conforme relatado por Gomes (Gomes, 2007), e com valores similares aos já descritos para um ciclo estral fisiológico (Ginther, 1992), o que levou ao entendimento de que a r-bST não interfere no número de folículos, quando empregada nesses momentos. Essa não interferência da somatotrofina pode estar relacionada com o tempo necessário para o desenvolvimento de receptores nos folículos, entre a fase primordial e a antral. Isso porque $o$ início do desenvolvimento folicular ocorre em períodos anteriores à sua identificação na onda folicular, iniciando-se mais precocemente e tendo tempo mais longo de acordo com o porte da espécie (Monniaux et al., 1997). Dessa forma, a comprovada influência direta e indireta do $\mathrm{GH}$ 
sobre o desenvolvimento folicular (Zaczek et al., 2002) pode não ter sido potencializada em decorrência do tempo entre o início do tratamento com r-bST e o acompanhamento folicular.

Mesmo não existindo diferenças quanto ao comportamento da onda folicular e ao número de folículos, houve uma interferência sobre os diâmetros foliculares. O diâmetro do folículo dominante apresentou crescimento mais rápido, o que demonstra a influência do r-bST no surgimento precoce das fases de emergência e divergência da onda folicular ovariana $(\mathrm{P}<0,05)$ (Fig. 2).

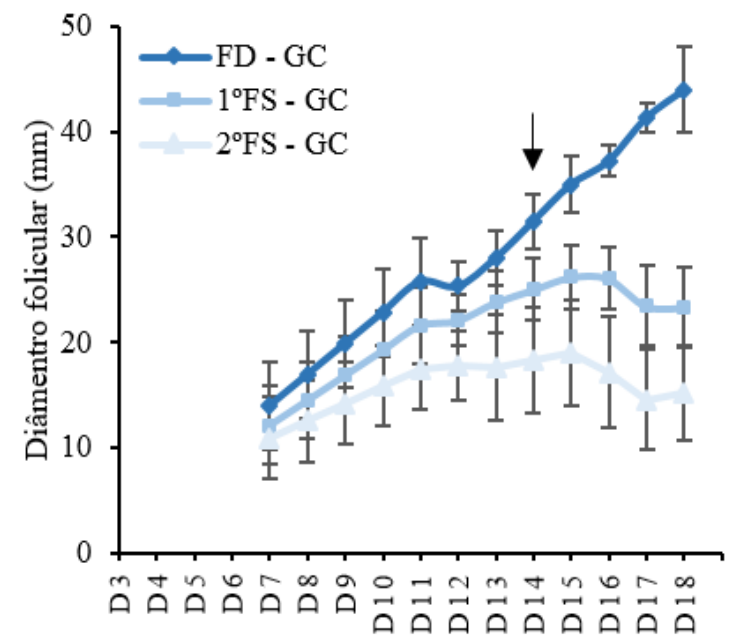

Dias do ciclo estral

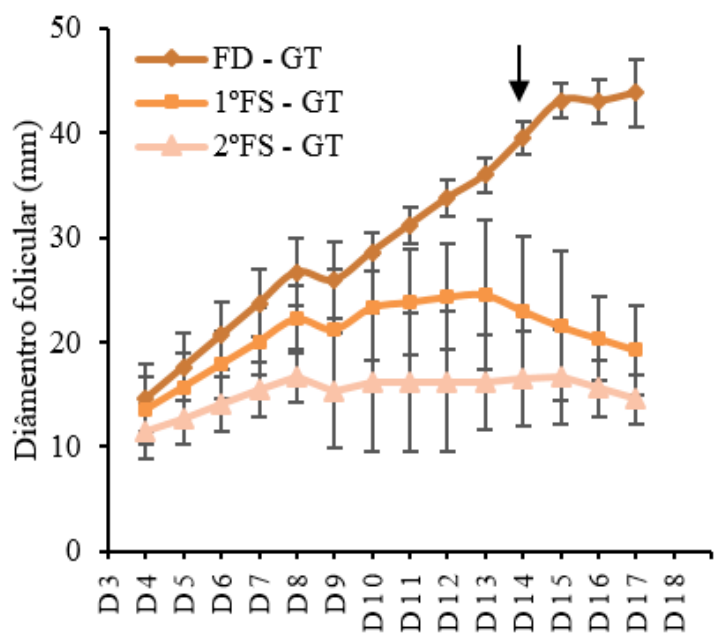

Dias do ciclo estral

Figura 1. Distribuição das médias ( \pm desvio-padrão) dos diâmetros dos folículos dominante (FD), $1^{\circ}$ subordinado $\left(1^{\circ} \mathrm{FS}\right)$ e $2^{\circ}$ subordinado $\left(2^{\circ} \mathrm{FS}\right)$ dos grupos controle (A) e tratamento $(\mathrm{B})$ no decorrer do ciclo estral de éguas tratadas (GT) ou não (GC) com r-bST. Segunda aplicação de r-bST ( $)$.

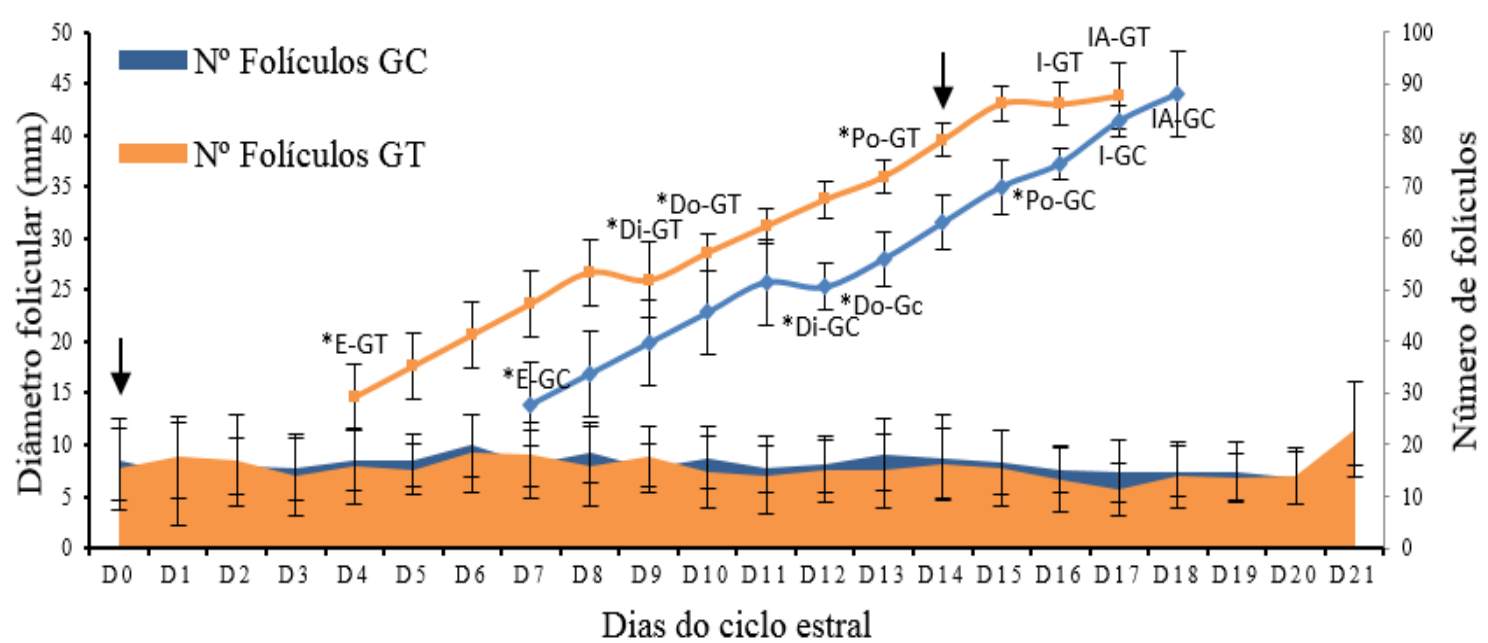

Figura 2. Distribuição das médias ( \pm desvio-padrão) do número de folículos (em área) e dos diâmetros foliculares (em linhas) estimados por meio das taxas de crescimento folicular e dos diâmetros das fases de emergência (E), divergência (Di), dominância (Do), pré-ovulatória (Po), indução ovulatória (I) e inseminação artificial (IA), no decorrer do ciclo estral de éguas tratadas (GT) ou não (GC) com r-bST. Aplicação do r-bST $(\downarrow)$. *Quando presente, representa diferenças significativas em relação aos dias do ciclo estral $(\mathrm{P}<0,05)$. 
A precocidade da onda folicular do GT levou a diferenças significativas nos dias das fases de emergência, divergência, dominância e préovulatória $(\mathrm{P} \leq 0,05)$, tendo essas ocorrido aproximadamente três dias mais cedo que no GC. Porém, as fases de indução ovulatória, inseminação artificial e ovulação foram semelhantes $(\mathrm{P}>0,05)$. Esses dados corroboram pesquisas na espécie suína (Echternkamp et al., 1992) e bovina (Gong et al., 1993)), que também observaram crescimento folicular acelerado nas fases iniciais da onda folicular, e a de Zulu et al., (2002), os quais demonstraram influência dos fatores de crescimento na dinâmica reprodutiva de bovinos. $\mathrm{O}$ momento esperado da emergência seria entre os dias nove e 12 do ciclo estral, com folículos em torno de $13 \mathrm{~mm}$ (Ginther et al., 2008a), sendo esses dias estatisticamente diferentes entre os grupos, com o $\mathrm{GC}$ apresentando valores próximos aos da literatura, provavelmente pela elevação dos níveis de IGFI, que interferem direta (Donadeu e Ginther,
2002) e indiretamente na dinâmica ovariana (Donadeu e Watson, 2007).

De forma semelhante ao folículo dominante, o maior subordinado ( $1^{\circ}$ folículo subordinado) alcançou diâmetros importantes e significativamente precoces em relação ao GC, atingindo $22 \mathrm{~mm}$ aproximadamente três dias mais cedo (Fig. 3), diâmetro utilizado como ponto de corte para indução da superovulação (MeyersBrown et al., 2011; Roser e Meyers-Brown, 2012). Os resultados superovulatórios ainda são muito variáveis entre as éguas e os tratamentos utilizados (Roser e Meyers-Brown, 2012), sendo o uso da r-bST considerado como uma possibilidade de melhorar os resultados de superovulação em equinos, por meio da elevação na concentração de IGF-I, já descrito como fator importante na superovulação em outras espécies, como em ratos e bovinos (Velazquez et al., 2009). Já o terceiro maior folículo ( $2^{\circ}$ folículo subordinado) não apresentou alteração em seu comportamento.

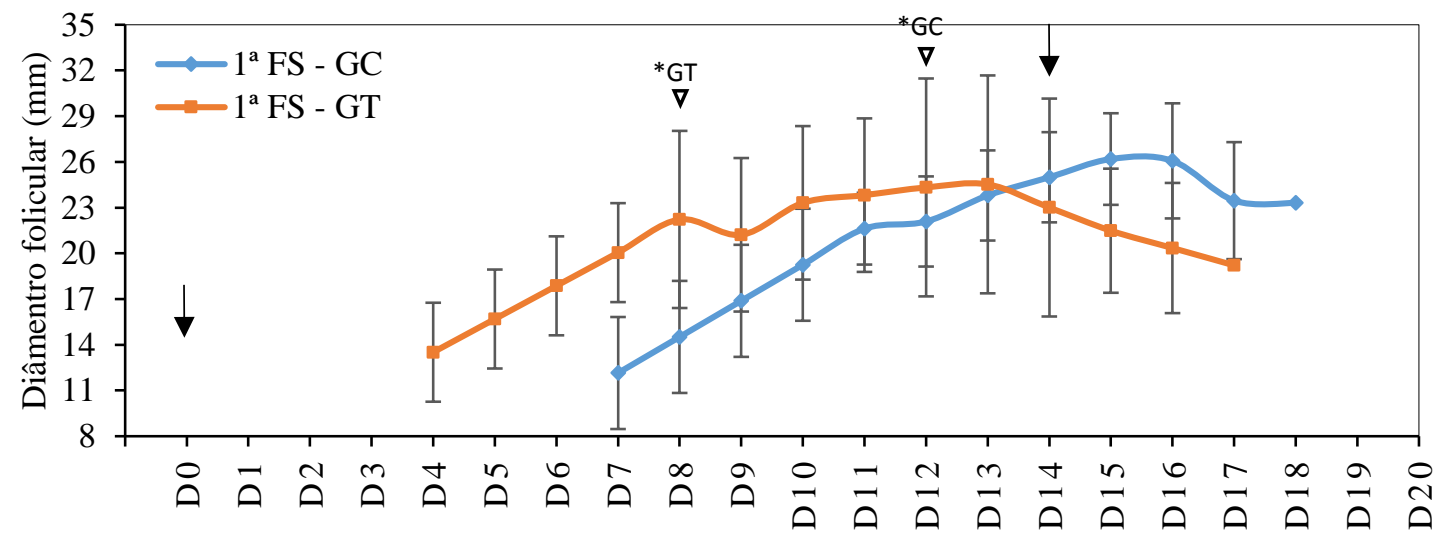

Dias do ciclo estral

Figura 3. Distribuição das médias ( \pm desvio-padrão) dos diâmetros do $1^{\circ}$ folículo subordinado $\left(1^{\circ} \mathrm{FS}\right)$ dos grupos controle (GC) e tratamento (GT), no decorrer do ciclo estral de éguas tratadas com r-bST. Aplicação do r-bST ( $\downarrow$ ). Folículo subordinado $\geq 22(\nabla)$. *Representa diferenças significativas em relação aos dias do ciclo estral entre grupos $(\mathrm{P}<0,05)$.

Mesmo existindo uma precocidade em algumas fases da onda folicular, essas se mantiveram igualitariamente separadas. Não ocorreu interferência sobre as taxas de crescimento folicular de nenhuma fase e em nenhuma categoria de folículo (Tab. 1), sendo o crescimento do folículo dominante semelhante ao descrito na literatura, que é em torno de $3 \mathrm{~mm}$ por dia (Ginther et al., 2008a). Porém, uma menor taxa de crescimento folicular no GT nas fases finais da onda folicular levou a uma semelhança na duração total do ciclo estral.

Embora haja semelhança entre os grupos quanto ao momento da ovulação, no D18 a maioria dos animais tratados já havia ovulado, contra uma pequena parcela do grupo controle (Fig. 4), o que demonstra, mais uma vez, a capacidade do 


\section{Ferreira et al.}

tratamento proposto em antecipar etapas do ciclo estral. Identificou-se apenas um ciclo curto para o GC, que pode ser explicado pela variação individual, pois, em casos como este, o principal fator de influência nos intervalos entre ovulações é a própria égua, que pode apresentar ciclos de
13 a 25 dias. Assim, as éguas com curtos intervalos entre ovulações já demonstram folículos > 30mm próximo ao D6 (Marinone et al., 2015), conforme se apresentou neste caso.

Tabela 1. Médias ( \pm desvio-padrão) dos dias do ciclo estral, diâmetros foliculares, taxa de crescimento folicular e vascularização folicular periférica das fases de emergência, divergência, dominância, préovulatória, indução ovulatória, inseminação artificial e ovulatória de éguas tratadas com r-bST

\begin{tabular}{|c|c|c|c|c|c|c|c|}
\hline \multirow{2}{*}{ Variáveis } & \multicolumn{7}{|c|}{ Fases da onda folicular } \\
\hline & Emergência & Divergência & Dominância & Pré-ovulatória & Indução & Inseminação & Ovulação \\
\hline \multicolumn{8}{|l|}{ Controle } \\
\hline Dia do ciclo (dia) & $6,6( \pm 3,0)^{A}$ & $11,7( \pm 2,5)^{\mathrm{A}}$ & $12,6( \pm 2,8)^{\mathrm{A}}$ & $15,8( \pm 3,0)^{\mathrm{A}}$ & $17,1( \pm 3,1)^{\mathrm{A}}$ & $18,2( \pm 2,7)^{\mathrm{A}}$ & $19,3( \pm 2,8)^{\mathrm{A}}$ \\
\hline Número de folículos & $19,7( \pm 7,7)^{\mathrm{Aa}}$ & $15,8( \pm 5,9)^{\mathrm{A}}$ & $15,2( \pm 5,4)^{\mathrm{A}}$ & $14,7( \pm 5,3)^{\mathrm{A}}$ & $14,5( \pm 6,5)^{\mathrm{A}}$ & $14,6( \pm 6,5)^{\mathrm{A}}$ & \\
\hline \multicolumn{8}{|l|}{ Folículo Dominante } \\
\hline Diâmetro folicular (mm) & $12,75( \pm 4,1)^{\mathrm{A}}$ & $24,72( \pm 2,3)^{\mathrm{A}}$ & $26,59( \pm 2,6)^{\mathrm{A}}$ & $36,39( \pm 1,5)^{\mathrm{A}}$ & $41,56( \pm 1,5)^{\mathrm{A}}$ & $43,99( \pm 4,1)^{\mathrm{A}}$ & \\
\hline Taxa de crescimento (mm) & $2,96( \pm 2,6)^{\mathrm{Aa}}$ & $1,99( \pm 1,1)^{\text {Аa }}$ & $3,5( \pm 1,4)^{\mathrm{Aa}}$ & $4,27( \pm 1,3)^{\mathrm{Aa}}$ & $2,24( \pm 2,9)^{\mathrm{Aa}}$ & & \\
\hline \multicolumn{8}{|l|}{$1^{\text {a }}$ Folículo Subordinado } \\
\hline Diâmetro folicular (mm) & $11,2( \pm 3,7)^{\mathrm{A}}$ & $21,36( \pm 2,4)^{\mathrm{A}}$ & $23,32( \pm 3,0)^{\mathrm{A}}$ & $26,36( \pm 3,0)^{\mathrm{A}}$ & $25,17( \pm 3,8)^{\mathrm{A}}$ & $24,63( \pm 3,8)^{\mathrm{A}}$ & \\
\hline Taxa de crescimento (mm) & $2,37( \pm 1,2)^{\mathrm{Aa}}$ & $2,44( \pm 1,9)^{\mathrm{Aa}}$ & $1,2( \pm 1,8)^{\mathrm{Aa}}$ & $-1,46( \pm 3,9)^{\mathrm{Aa}}$ & $-0,16( \pm 2,9)^{\mathrm{Aa}}$ & & \\
\hline \multicolumn{8}{|l|}{$2^{\mathrm{a}}$ Folículo Subordinado } \\
\hline Diâmetro folicular (mm) & $0,24( \pm 3,9)^{\mathrm{A}}$ & $17,54( \pm 3,3)^{\mathrm{A}}$ & $17,3( \pm 5,0)^{\mathrm{A}}$ & $17,33( \pm 5,3)^{\mathrm{A}}$ & $16,24( \pm 4,7)^{\mathrm{A}}$ & $16,7( \pm 4,5)^{\mathrm{A}}$ & \\
\hline Taxa de crescimento (mm) & $1,65( \pm 0,7)^{\mathrm{Aa}}$ & $0,8( \pm 2,8)^{\mathrm{Aa}}$ & $0,69( \pm 3,1)^{\mathrm{Aa}}$ & $-0,8( \pm 2,0)^{\text {Aa }}$ & $0,66( \pm 3,3)^{\mathrm{Aa}}$ & & \\
\hline \multicolumn{8}{|l|}{ TRATAMENTO } \\
\hline Dia do ciclo (dia) & $4,1( \pm 2,2)^{\mathrm{B}}$ & $8,5( \pm 1,2)^{\mathrm{B}}$ & $9,5( \pm 1,4)^{\mathrm{B}}$ & $13,2( \pm 1,6)^{\mathrm{B}}$ & $15,5( \pm 1,3)^{\mathrm{A}}$ & $16,8( \pm 1,8)^{\mathrm{A}}$ & $17,8( \pm 1,8)^{\mathrm{A}}$ \\
\hline Número de folículos & $16,8( \pm 5,8)^{\mathrm{Aa}}$ & $15,6( \pm 4,7)^{\mathrm{Aa}}$ & $16,2( \pm 6,2)^{\mathrm{Aa}}$ & $17,0( \pm 6,5)^{\mathrm{Aa}}$ & $13,0( \pm 5,0)^{\mathrm{Aa}}$ & $12,8( \pm 5,4)^{\mathrm{Aa}}$ & $16,8( \pm 5,8)^{\mathrm{Aa}}$ \\
\hline \multicolumn{8}{|l|}{ Folículo Dominante } \\
\hline Diâmetro folicular (mm) & $14,92( \pm 3,2)^{\mathrm{A}}$ & $24,21( \pm 3,7)^{\mathrm{A}}$ & $27,34( \pm 1,8)^{\mathrm{A}}$ & $36,69( \pm 1,6)^{\mathrm{A}}$ & $42,86( \pm 2,1)^{\mathrm{A}}$ & $43,81( \pm 3,3)^{\mathrm{A}}$ & \\
\hline Taxa de crescimento (mm) & $3,02( \pm 2,6)^{\mathrm{Aa}}$ & $3,48( \pm 2,4)^{\mathrm{Aa}}$ & $2,57( \pm 0,5)^{\mathrm{Aa}}$ & $3,53( \pm 2,6)^{\mathrm{Aa}}$ & $0,28( \pm 2,8)^{\mathrm{Aa}}$ & $3,02( \pm 2,6)^{\mathrm{Aa}}$ & \\
\hline \multicolumn{8}{|l|}{$1^{\mathrm{a}}$ Folículo Subordinado } \\
\hline Diâmetro folicular (mm) & $13,73( \pm 3,2)^{\mathrm{A}}$ & $19,01( \pm 5,8)^{\mathrm{A}}$ & $23,06( \pm 5,0)^{\mathrm{A}}$ & $24,83( \pm 7,2)^{\mathrm{A}}$ & $24,15( \pm 4,1)^{\mathrm{A}}$ & $22,89( \pm 4,3)^{\mathrm{A}}$ & \\
\hline Taxa de crescimento (mm) & $2,18( \pm 4,5)^{\mathrm{Aa}}$ & $4,41( \pm 3,7)$ & $0,51( \pm 1,2)$ & $-1,52( \pm 6,5)$ & $-1,14( \pm 2,3)$ & & \\
\hline \multicolumn{8}{|l|}{$2^{\mathrm{a}}$ Folículo Subordinado } \\
\hline Diâmetro folicular (mm) & $11,56( \pm 2,6)^{\mathrm{A}}$ & $14,3( \pm 5,5)^{\mathrm{A}}$ & $16,09( \pm 6,7)^{\mathrm{A}}$ & $16,16( \pm 4,5)^{\mathrm{A}}$ & $17,27( \pm 2,8)^{\mathrm{A}}$ & $16,04( \pm 2,3)^{\mathrm{A}}$ & \\
\hline Taxa de crescimento (mm) & $1,34( \pm 2,9)^{\mathrm{Aa}}$ & $2,06( \pm 5,7)^{\mathrm{Aa}}$ & $0,06( \pm 1,2)^{\mathrm{Aa}}$ & $0,24( \pm 3,5)^{\mathrm{Aa}}$ & $-1,02( \pm 1,2)^{\mathrm{Aa}}$ & & \\
\hline
\end{tabular}

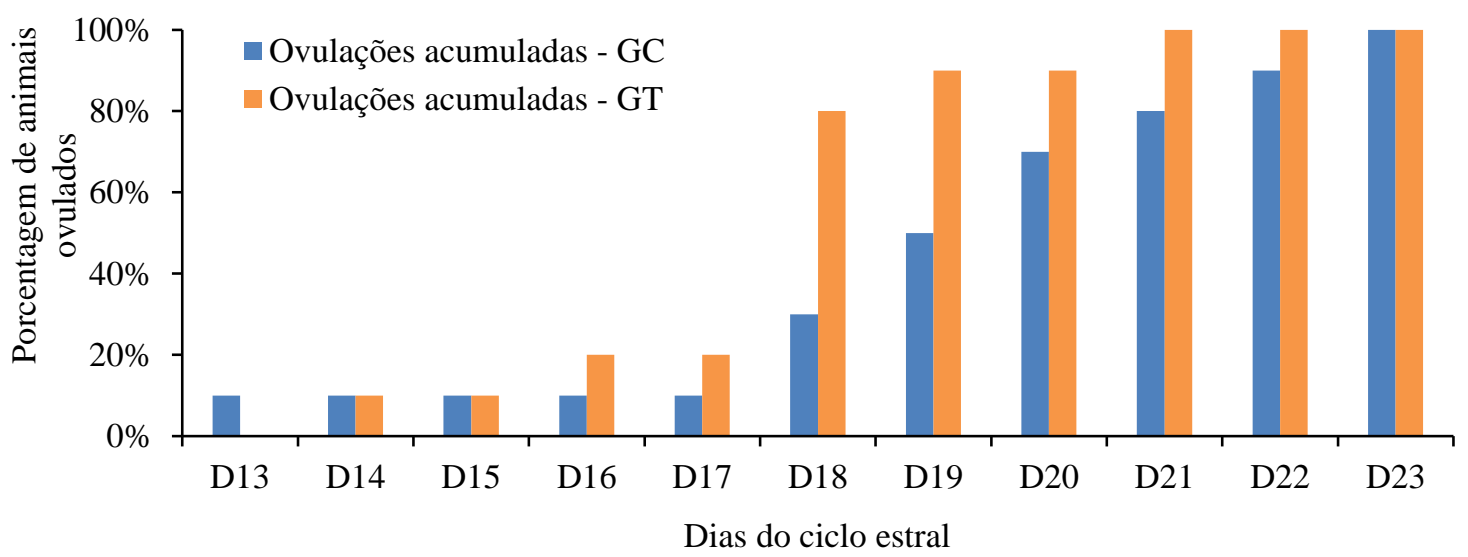

Figura14. Distribuição das porcentagens acumuladas de ovulações no decorrer do ciclo estral de éguas tratadas (GT) ou não (GC) com r-bST. 
$\mathrm{Na}$ análise das variáveis embrionárias, não foram constatadas diferenças entre os grupos $(\mathrm{P}>0,05)$ (Tab. 2), o que também foi observado em outras pesquisas utilizando r-bST em protocolos superovulatórios em equinos (Gomes, 2007) e bovinos (Gong et al., 1993; Neves, et al, 2005). Da mesma forma, a emergência precoce, em conjunto com um maior tempo até a indução ovulatória, não influenciou tais variáveis, visto que no GT o tempo de duração do folículo dominante até ele ser induzido foi de $6( \pm 0,9)$ contra 4,5 $( \pm 1,43)$ dias para o GC, resultando em uma diferença significativa de 1,5 dia a mais para o GT $(\mathrm{P}=0,013)$. Poder-se-ia esperar alguma interferência pelo maior tempo de desenvolvimento oocitário, porém um fator mais importante que interfere na qualidade do oócito é o tamanho folicular final (Hyttel et al., 1997), e este foi semelhante entre os grupos, já que a indução da ovulação dos folículos ocorreu em função do tamanho e não do tempo de desenvolvimento.
Isso posto, poder-se-ia inferir que o tratamento favoreceu uma maior homogeneidade dos estágios embrionários por uma maior padronização nos momentos da ovulação. Porém, a existência de um blastocisto inicial encontrado no GC, mesmo sendo possível de ocorrer nessa fase (Mckinnon e Squires, 2007), foi proveniente de um ciclo no qual a ovulação pode ter ocorrido logo após a avaliação ginecológica, realizada no período da manhã, estando, portanto, mais próximo do sétimo dia após ovulação do que do sexto, pois a ovulação só foi considerada na avaliação com 48 horas da IA. As ovulações foram assim consideradas devido ao fato de a maioria das éguas ovularem durante a noite (Romano et al., 1998) e responderem ao hCG em torno de 36 horas após a aplicação (Ginther et al., 2008b). Dessa maneira, quando a ovulação não foi identificada no dia seguinte à IA, esperava-se que a ovulação tivesse ocorrido nas próximas 12 horas, o que provavelmente ocorreu em sua maioria, vistos os estágios embrionários encontrados.

Tabela 2. Taxa de recuperação embrionária por coleta, número, estágio e qualidade embrionária de éguas tratadas com r-bST

\begin{tabular}{llll}
\hline \multirow{2}{*}{ Variável } & \multicolumn{1}{l}{ Grupo } & \\
\cline { 3 - 4 } & & Controle & Tratamento \\
\hline \multicolumn{2}{l}{ Taxa de recuperação por coleta } & $90,00 \%$ & $70,00 \%$ \\
\multirow{2}{*}{$\begin{array}{l}\text { Eúmero total de estruturas/embriões de desenvolvimento } \\
\text { embrionário }\end{array}$} & Não fecundado & $9 / 8$ & $7 / 7$ \\
& Mórula compacta & $1(12,5 \%)$ & $0(0,0 \%)$ \\
& Mórula & $2(25,0 \%)$ & $3(42,9 \%)$ \\
Qualidade embrionária & Blastocisto inicial & $5(62,5 \%)$ & $4(57,1 \%)$ \\
& Excelente & $1(12,5 \%)$ & $0(0,0 \%)$ \\
& Regular & $6(75,0 \%)$ & $6(85,7 \%)$ \\
& Pobre & $1(12,5 \%)$ & $1(14,3 \%)$ \\
\end{tabular}

Os demais estágios e qualidades não foram encontrados.

Em um dos ciclos estrais em que não houve recuperação embrionária no GT, a inseminação foi realizada com a égua já ovulada; em todos os demais ciclos, os animais foram inseminados antes da ovulação. Resultados negativos são esperados quando se insemina uma égua após ovulação, devido ao tempo de vida do oócito em conjunto com a necessidade da capacitação espermática, levando a falhas de fecundação quando o procedimento não foi realizado em períodos até 12 horas após a ovulação (Newcombe et al., 2011). Por outro lado, em $30 \%$ dos casos, em ambos os grupos, a ovulação ocorreu entre 24 e 48 horas após inseminação; desses, $100 \%$ redundaram em embriões. Esse resultado confirma a necessidade de inseminação de equinos apenas a cada 48 horas, possibilitada pela viabilidade espermática (Saturnino et al., 2002).

Diante disso, mesmo sem influência sobre o modelo da onda folicular e os resultados comerciais finais na produção de embriões, o tratamento pode levar a uma redução significativa da duração do ciclo estral em aproximadamente três dias se a indução da ovulação for realizada quando o diâmetro folicular atingir o limiar de $35 \mathrm{~mm}$, além de permitir o início mais cedo de um protocolo de superovulação. Isso possibilita aumentar o 
número de coletas de embrião em um mesmo período de tempo, quando utilizados vários ciclos consecutivos, o que é desejável nas centrais de reprodução.

\section{CONCLUSÕES}

A r-bST influenciou o ciclo estral das éguas tratadas, levando à antecipação no desenvolvimento dos folículos, podendo reduzir o tempo total do ciclo estral equino e favorecer tratamentos superovulatórios. Porém, a r-bST, quando aplicada durante o ciclo estral, não altera a quantidade de folículos, o tipo e o número das ondas foliculares, bem como a qualidade e a quantidade de embriões.

\section{REFERÊNCIAS}

ALVES, K.A.; ALVES, B.G.; GASTAL, G.D.A. et al. The mare model to study the effects of ovarian dynamics on preantral follicle features. PLoS One, v.11, 2016.

BORST, S.E. Interventions for sarcopenia and muscle weakness in older people. Age Ageing, v.33, p.548-555, 2004.

BUONOMO, F.C.; RUFFIN, D.S.; BRENDEMEUHL, J.P. et al. The Effects of Bovine Somatotropin (bST) and Porcine Somatotropin (pST) on growth factor and metabolic variables in horses. J. Anim. Sci., v.74, p.886-894, 1996.

COCHRAN, R.A.; LEONARDI-CATTOLICA, A.A.; SULLIVAN, M.R. et al. The effects of equine somatotropin (eST) on follicular development and circulating plasma hormone profiles in cyclic mares treated during different stages of the estrous cycle. Domest. Anim. Endocrinol., v.16, p.57-67, 1999.

CURI, P.R. Metodologia e análise da pesquisa em ciências biológicas. 2.ed. Botucatu: Tipomic, 1998.

CUSHMAN, R.A.; HEDGPETH, V.S.; ECHTERNKAMP, S.E.; BRITT, J.H. Evaluation of numbers of microscopic and macroscopic follicles in cattle selected for twinning. J. Anim. Sci., v.78, p.1564-1567, 2000.
DE KOCK, S.S.; RODGERS, J.P.; SWANEPOEL, B.C.; GUTHRIE, A.J. Administration of bovine, porcine and equine growth hormone to the horse: effect on insulinlike growth factor-I and selected IGF binding proteins. J. Endocrinol., v.171, p.163-171, 2001.

DONADEU, F.X.; GINTHER, O.J. Changes in concentrations of follicular fluid factors during follicle selection in mares. Biol. Reprod., v.66, p.1111-1118, 2002.

DONADEU, F.X.; PEDERSEN, H.G. Follicle development in mares. Reprod. Domest. Anim., v.43, Suppl.2, p.224-231, 2008.

DONADEU, F.X.; WATSON, E.D. Seasonal changes in ovarian activity: lessons learnt from the horse. Anim. Reprod. Sci., v.100, p.225-242, 2007.

ECHTERNKAMP, S.E.; SPICERT, L.J.; KLINDT, J. et al. Administration of porcine somatotropin by a sustained-release implant: effects on follicular growth, concentrations of steroids and insulin-like growth factor $\mathrm{i}$, and insulin-like growth factor binding protein activity in follicular fluid of control, L. J. Anim. Sci., v.72, p.2431-2440, 1992.

GINTHER, O. Reproductive biology of the mare: basic and applied aspects. 2.ed. Wisconsin: [s.n.], 1992.

GINTHER, O.J. Selection of the dominant follicle in cattle and horses. Anim. Reprod. Sci., v.60-61, p.61-79, 2000.

GINTHER, O.J.; GASTAL, E.L.; GASTAL, M.O.; BEG, M.A. Dynamics of the equine preovulatory follicle and periovulatory hormones: what's new? J. Equine Vet. Sci., v.28, p.454-460, 2008a.

GINTHER, O.J.; GASTAL, M.O.; GASTAL, E.L. et al. Effects of age on follicle and hormone dynamics during the oestrous cycle in mares. Reprod. Fertil. Dev., v.20, p.955-963, 2008 b.

GOMES, G.M. Efeito da somatotrofina recombinante bovina ( $r b S T$ ) sobre a resposta superovulatória e recuperação embrionária em éguas tratadas com extrato de pituitária eqüina ( $E P E$ ). 2007. 75f. Tese (Doutorado) - Faculdade de Medicina Veterinária e Zootecnia, Universidade Estadual Paulista, Botucatu, SP. 
GONG, J.G.; BRAMLEY, T.A. WILMUT, I.; WEBB, R. The effect of recombinant bovine somatotropin on ovarian follicular growth and development in heifers. J. Reprod. Fertil., v.97, p.247-254, 1993.

GURGEL, J.R.C.; VIANA, C.H.C.; PEREZ, E.G.A.; NICHI, M. Dinâmica folicular em éguas: aspectos intrafoliculares. Rev. Bras. Reprod. Anim., v.32, p.122-132, 2008.

HULL, K.L.; HARVEY, S. Growth hormone and reproduction: a review of endocrine and autocrine/paracrine interactions. Int. J. Endocrinol., v.2014, 2014. Disponível em: <https://doi.org/10.1155/2014/234014 >. Acessado em: 5 dez. 2017.

HYTTEL, P.; FAIR, T.; CALLESEN, H.; GREVE, T. Oocyte growth, capacitation and final maturation in cattle. Theriogenology, v.47, p.23-32, 1997.

KIRBY, C.J.; WILSON, S.J.; LUCY, M.C. Response of dairy cows treated with bovine somatotropin to a luteolytic dose of prostaglandin F2 $\alpha$. J. Dairy Sci., v.80, p.286294, 1997.

MARINONE, A.I.; LOSINNO, L.; FUMUSO, E. et al. The effect of mare's age on multiple ovulation rate, embryo recovery, post-transfer pregnancy rate, and interovulatory interval in a commercial embryo transfer program in Argentina. Anim. Reprod. Sci., v.158, p.53-59, 2015.

MCCUE, P.M. Transferência de embriões em equinos: avaliação do embrião. Rev. Educ. Cont. Med. Vet. Zootec., v.9, p.80-83, 2011.

MCKINNON, A.O.; SQUIRES, E.L. Embryo transfer and related technologies. In: SAMPER, J.C.; PYCOCK, J.F.; MCKINNON, A.O. Current therapy in equine reproduction. Philadelphia: Elsevier, 2007. p.319-334.

MEYERS-BROWN, G.; BIDSTRUP, L.A.; FAMULA, T.R. et al. Treatment with recombinant equine follicle stimulating hormone (reFSH) followed by recombinant equine luteinizing hormone (reLH) increases embryo recovery in superovulated mares. Anim. Reprod. Sci., v.128, p.52-59, 2011.
MONNIAUX, D.; MONGET, P.; BESNARD, N. et al. Growth factors and antral follicular development in domestic ruminants. Theriogenology, v.47, p.3-12, 1997.

MOREIRA, F.; BADINGA, L.; BURNLEY, C.; THATCHER, W.W. Bovine somatotropin increases embryonic development in superovulated cows and improves post-transfer pregnancy rates when given to lactating recipient cows. Theriogenology, v.57, p.1371-1387, 2002.

NEVES, E.F.; RAMOS, A.F.; MARQUES, A.P. Pré-tratamento com somatotropina bovina (rbST) na superovulação de doadoras da raça Holandesa. Arq. Bras. Med. Vet. Zootec., v.57, p.205-209, 2005.

NEWCOMBE, J.R.; PACCAMONTI, D.; CUERVO-ARANGO, J. Reducing the examination interval to detect ovulation below $12 \mathrm{~h}$ does not improve pregnancy rates after postovulatory insemination with frozen/thawed semen in mares. Anim. Reprod. Sci., v.123, p.6063, 2011 .

NORMAN, A.W.; LITWACK, G. Anterior pituitary hormones. In: Hormones. 2.ed. California: Academic Press, 1997. p.133-168.

ROMANO, M.A.; MUCCIOLO, R.G.; SILVA, A.E.D.F. Biologia reprodutiva de éguas: estudo do ciclo estral e momento de ovulação. Braz. J. Vet. Res. Anim. Sci., v.35, p.25-28, 1998.

ROSER, J.F.; MEYERS-BROWN, G. Superovulation in the mare: a work in progress. J. Equine Vet. Sci., v.32, p.376-386, 2012.

SÁ FILHO, M.F.; CARVALHO, N.A.T.; Gimenes, L.U. et al. Effect of recombinant bovine somatotropin (bST) on follicular population and on in vitro buffalo embryo production. Anim. Reprod. Sci., v.113, p.51-59, 2009.

SATURNINO, H.M.; MONTEIRO, J.; SILVA, M.D. et al. Efeito do intervalo das duas últimas inseminações sobre a fertilidade de éguas inseminadas com sêmen fresco diluído. Rev. Bras. Zootec., v31, p.1143-1149, 2002. 
SPICER, L.J.; ALPIZAR, E.; ECHTERNKAMP, S.E. Effects of insulin, insulin-like growth factor $\mathrm{I}$, and gonadotropins on bovine granulosa cell proliferation, progesterone production, estradiol production, and(or) insulin-like growth factor I production in vitro. J. Anim. Sci., v.71, p.12321241, 1993.

SQUIRES, E.L.; CARNEVALE, E.M.; MCCUE, P.M.; BRUEMMER, J.E. Embryo technologies in the horse. Theriogenology, v.59, p.151-170, 2003.

VELAZQUEZ, M.A.; ZARAZA, J.; OROPEZA, A. et al. The role of IGF1 in the in vivo production of bovine embryos from superovulated donors. Reproduction, v.137, p.161-180, 2009.
ZACZEK, D.; HAMMOND, J.; SUEN, L. et al. Impact of growth hormone resistance on female reproductive function: new insights from growth hormone receptor knockout mice. Biol. Reprod., v.67, p.1115-1124, 2002.

ZULU, V.C.; NAKAO, T.; SAWAMUKAI, Y. Insulin-like growth factor-I as a possible hormonal mediator of nutritional regulation of reproduction in cattle. J. Vet. Med. Sci., v.64, p.657-665, 2002. 